in vivo $35: 1211-1215(2021)$

doi:10.21873/invivo.12371

\title{
Efficacy of Paclitaxel-based Chemotherapy After Progression on Nivolumab for Head and Neck Cancer
}

\author{
YASUYOSHI SATO $^{1}$, NAOKI FUKUDA ${ }^{1}$, YU FUJIWARA $^{1}$, XIAOFEI WANG ${ }^{1}$, \\ TETSUYA URASAKI ${ }^{1}$, AKIHIRO OHMOTO ${ }^{1}$, KENJI NAKANO ${ }^{1}$, MAKIKO ONO ${ }^{1}$, \\ JUNICHI TOMOMATSU $^{1}$, HIROKI MITANI ${ }^{2}$ and SHUNJI TAKAHASHI ${ }^{1}$ \\ Departments of ${ }^{1}$ Medical Oncology, and ${ }^{2}$ Head and Neck Oncology, \\ The Cancer Institute Hospital of Japanese Foundation for Cancer Research, Tokyo, Japan
}

\begin{abstract}
Background/Aim: In the CheckMate-141 trial regarding head and neck cancer (HNC), nivolumab conferred a survival benefit to patients. However, the best treatment sequence of chemotherapy and anti-PD-1/PD-L1 therapy in these cancers is unclear. Patients and Methods: This was an observational study using data collected prospectively from $97 \mathrm{HNC}$ patients treated with nivolumab at our institutions. Twenty-two HNC patients who received paclitaxel-based chemotherapy before (pre-PTX, n=12) and after (post-PTX, $n=10$ ) nivolumab were evaluated. Results: The median follow-up time was 15.9 months (range=6.9-35.9 months). There was a significant difference in the overall response rate $(O R R)$ between pre-PTX $(17 \%)$ and post-PTX (70\%) ( $p=0.027)$. Similarly, time to progression (TTP) was significantly longer after nivolumab than before nivolumab (post-PTX, 7.4 months; pre-PTX, 4.9 months, $p=0.020$ ). Conclusion: Paclitaxel-based chemotherapy had a better $O R R$ and TTP after nivolumab than before nivolumab for $H N C$. The sequential administration of anti-PD-1 therapy followed by paclitaxel-based chemotherapy could be a better strategy for HNC.
\end{abstract}

Immune checkpoint inhibitors, such as those that block interactions between cytotoxic T-lymphocyte antigen-4 and its ligands CD80/CD86 or between programmed death-1 (PD-1) and its ligand PD-L1, show survival benefits for patients with various types of cancer $(1,2)$.

This article is freely accessible online.

Correspondence to: Yasuyoshi Sato, The Cancer Institute Hospital of Japanese Foundation for Cancer Research, Japan, 3-8-31 Ariake, Koto-ku, Tokyo 135-8550, Japan. Tel: +81 35200111, Fax: +81 335200141, e-mail: yasuyoshi_s@ hotmail.com

Key Words: Head and neck cancer, salvage chemotherapy, immune checkpoint inhibitor, nivolumab, PD-1.
In head and neck cancer (HNC), the phase 3 CheckMate141 trial, a comparison between the investigator's choice of therapy and nivolumab, an anti-human PD-1 monoclonal antibody, demonstrated that nivolumab significantly extended the overall survival (OS) of patients with recurrent or metastatic HNC who had received platinum-based chemotherapy and were ineligible for local treatment $(3,4)$. Nivolumab along with paclitaxel-based chemotherapy are currently regarded as standard second-line treatments for recurrent or metastatic HNC in Japan. Moreover, several studies have reported that the efficacy of nivolumab for patients with HNC subtypes and primary sites excluded from the CheckMate-141 trial was comparable with that obtained in the CheckMate-141 trial $(5,6)$.

In the CheckMate-141 trial, HNC patients treated with nivolumab showed no benefit in terms of progression-free survival (PFS) compared with the chemotherapy arm, despite a benefit in OS. This survival pattern was observed in several trials of anti-PD-1/PD-L1 therapy for non-small cell lung cancer (NSCLC) $(7,8)$ and renal cell carcinoma (9). These phenomena are partly explained by the increased sensitivity to chemotherapy after exposure to anti-PD-1/PD-L1 therapy. Several previous studies have shown a high overall response rate (ORR) to chemotherapy after anti-PD-1 therapy: $39 \%$ in NSCLC (10), 64\% in urothelial cancer (11).

For HNC, a retrospective study of 82 patients with recurrent or metastatic $\mathrm{HNC}$ who had progressed on immune checkpoint inhibitors (ICI) evaluating response to salvage chemotherapy (SCT) also showed high ORR (30\%) (12). However, it is unclear which treatment sequence of chemotherapy and ICI achieves optimal antitumor effects for HNC. First, this study evaluated the efficacy of SCT after ICI without comparing that of chemotherapy before ICI. Second, the SCT contained too many types of regimens (paclitaxel, docetaxel, cisplatin, and carboplatin with or without cetuximab) at various lines (from second to sixth line) to enable a comparison with the historical control. And there was no report comparing the efficacy of same 
chemotherapy regimen before and after anti-PD-1/PD-L1 therapy in patients with HNC.

To address these issues, the present study evaluated the efficacies of paclitaxel-based chemotherapy administered before and after nivolumab in patients with HNC from realworld data and the best sequence of chemotherapy and immune checkpoint inhibitors.

\section{Patients and Methods}

Patients. We retrospectively analyzed prospectively collected data from 97 consecutive patients with recurrent or metastatic HNC who began treatment with nivolumab at The Cancer Institute Hospital of Japanese Foundation for Cancer Research (JFCR) between May 2017 and December 2019. HNC patients who received paclitaxelcontaining chemotherapy before or after nivolumab and for whom efficacy data were available (hereafter referred to as pre-PTX and post-PTX, respectively) were evaluated.

Nivolumab was administered at a dose of $3 \mathrm{mg} / \mathrm{kg}$ body weight every 2 weeks from May 2017 to mid-September 2018 and was then administered at a fixed dose of $240 \mathrm{mg}$ every 2 weeks from midSeptember 2018 to December 2020 (data cutoff for the present study), according to the changes in the guidelines approved by the Japanese Ministry of Health, Labour and Welfare. Paclitaxel was administered at a dose of $80 \mathrm{mg} / \mathrm{m}^{2}$ with or without cetuximab at a dose of $250 \mathrm{mg} / \mathrm{m}^{2}$ (400 mg/m², first time only) every week. All treatment was continued until unacceptable adverse effects occurred or the disease progressed.

The study was approved by the institutional review board of the Cancer Institute Hospital of the JFCR (no. 2020-1005). The study was conducted in accordance with the Helsinki Declaration of 1964 and later versions. Because the data were reported anonymously, the requirement for informed consent was waived.

Statistical analysis. All patients' characteristics were compared using Fisher's exact test, except for age, which was compared using $t$-test. Time to progression (TTP) was estimated using the KaplanMeier method and the log-rank test. Data were censored on December 28, 2020. Patients who were lost to follow-up were censored at the date of last contact or follow-up. TTP was calculated from the date of the paclitaxel initiation to the date of disease progression. Tumor response was evaluated according to the Response Evaluation Criteria in Solid Tumors, version 1.1., based on computed tomography findings. The best overall response was assessed as complete response (CR), partial response (PR), stable disease (SD), or progressive disease (PD), and non-CR/non-PD. The ORR corresponded to the sum of the CR and PR rates.

All statistical analyses were performed with EZR (Saitama Medical Center, Jichi Medical University, Saitama, Japan), which is a graphical user interface for R (www.r-project.org). More precisely, it is a modified version of $\mathrm{R}$ commander designed to add statistical functions frequently used in biostatistics (13).

\section{Results}

Patient characteristics. Among all patients, 15 received paclitaxel-containing chemotherapy before nivolumab (prePTX). Two patients who suffered from severe adverse events
Table I. The characteristics of 22 head and neck cancer patients.

\begin{tabular}{|c|c|c|c|}
\hline & $\begin{array}{c}\text { pre-PTX } \\
(\mathrm{N}=12)\end{array}$ & $\begin{array}{l}\text { post-PTX } \\
(\mathrm{N}=10)\end{array}$ & $p$-Value \\
\hline \multicolumn{4}{|l|}{ Age (year) } \\
\hline Median (range) & $65(46-75)$ & $65(51-77)$ & 0.42 \\
\hline Gender male, n (\%) & $12(100)$ & $9(90)$ & 0.46 \\
\hline Smoking habit, n (\%) & & & 0.079 \\
\hline Current & $7(58)$ & $3(30)$ & \\
\hline Former & $5(42)$ & $3(30)$ & \\
\hline Never & $0(0)$ & $4(40)$ & \\
\hline \multicolumn{4}{|l|}{$\begin{array}{l}\text { ECOG performance status } \\
\text { before PTX and Nivo }\end{array}$} \\
\hline 0 & $8(67)$ & $4(40)$ & \\
\hline 1 & $4(33)$ & $6(60)$ & \\
\hline Location of primary tumor, $\mathrm{n}(\%)$ & & & 0.93 \\
\hline Oral cavity & $1(8)$ & $1(10)$ & \\
\hline Nasopharynx & $1(8)$ & $1(10)$ & \\
\hline Oropharynx & $4(33)$ & $1(10)$ & \\
\hline Hypopharynx & $3(25)$ & $2(20)$ & \\
\hline Larynx & $1(8)$ & $2(20)$ & \\
\hline $\begin{array}{l}\text { Nasal cavity and paranasal } \\
\text { sinuses }\end{array}$ & $2(17)$ & $3(30)$ & \\
\hline Histological diagnosis, n (\%) & & & - \\
\hline Squamous cell carcinoma (SCC) & $12(100)$ & $10(100)$ & \\
\hline \multicolumn{4}{|l|}{ Recurrent or metastatic } \\
\hline Recurrent & $10(83)$ & $10(100)$ & \\
\hline Metastatic & $2(17)$ & $0(0)$ & \\
\hline $\begin{array}{l}\text { Number of chemotherapies } \\
\text { before PTX and Nivo, n (\%) }\end{array}$ & & & 0.81 \\
\hline 0 & $7(58)$ & $7(70)$ & \\
\hline 1 & $4(33)$ & $2(20)$ & \\
\hline 2 & $1(8)$ & $1(10)$ & \\
\hline $\begin{array}{l}\text { Regimens of chemotherapies } \\
\text { before PTX and Nivo, n (\%) }\end{array}$ & & & 1.00 \\
\hline $\begin{array}{l}\text { Fluorouracil+cisplatin+ } \\
\text { cetuximab }\end{array}$ & $3(25)$ & $2(20)$ & \\
\hline Fluorouracil+cisplatin & $0(0)$ & $1(10)$ & \\
\hline Docetaxel+cisplatin & $1(8)$ & $0(0)$ & \\
\hline Afatinib & $1(8)$ & $0(0)$ & \\
\hline Tegafur gimeracil oteracil & $1(8)$ & $0(0)$ & \\
\hline $\begin{array}{l}\text { Regimen of PTX-based } \\
\text { chemotherapy, n (\%) }\end{array}$ & & & 0.62 \\
\hline PTX with cetuximab & $10(83)$ & $7(70)$ & \\
\hline PTX alone & $2(17)$ & $3(30)$ & \\
\hline
\end{tabular}

SD: Standard deviation; ECOG: Eastern Cooperative Oncology Group; PTX: paclitaxel; Nivo: nivolumab; AUC: area under the curve; LS: least squares; NE: not estimable.

gave up paclitaxel-based chemotherapy at first cycle and a patient rechallenged with paclitaxel after progression on Nivolumab. These three patients were excluded from this analysis and 12 patients were enrolled to this study. Ten patients received paclitaxel-containing chemotherapy after nivolumab (post-PTX). They did not receive paclitaxel before nivolumab.

The characteristics of these 22 patients are shown in Table I. The median observation time was 15.9 months (range=6.9- 
Table II. The best overall response of paclitaxel-containing therapy in 22 head and neck cancer patients.

\begin{tabular}{lccc}
\hline & $\begin{array}{c}\mathrm{PTX} \rightarrow \text { Nivo } \\
(\mathrm{N}=12)\end{array}$ & $\begin{array}{c}\text { Nivo } \rightarrow \text { PTX } \\
(\mathrm{N}=10)\end{array}$ & $p$-Value \\
\hline CR, n (\%) & $0(0)$ & $0(0)$ & \\
PR, n (\%) & $2(17)$ & $7(70)$ & \\
SD, n (\%) & $6(50)$ & $2(20)$ & \\
PD, n (\%) & $3(25)$ & $1(10)$ & \\
Non-CR/non-PD, n (\%) & $1(8)$ & $0(0)$ & \multirow{2}{*}{0.027} \\
ORR, n (\%) & $2(17)$ & $7(70)$ & \\
\hline
\end{tabular}

PTX: Paclitaxel; CR: complete response; PR: partial response; SD: stable disease; PD: progressive disease; ORR: overall response rate.

35.9 months) after the earlier date of nivolumab or paclitaxel initiation. Fisher's exact test (or $t$-test for age) revealed no significant differences in patients' characteristics between the pre-PTX group and the post-PTX group (Table I). All patients had squamous cell carcinoma.

Efficacy of paclitaxel-based chemotherapy before and after nivolumab. The median TTP was 4.9 months [95\% confidence interval $(\mathrm{CI})=3.0-6.2]$ in the pre-PTX group, and 7.4 months $(95 \% \mathrm{CI}=1.4-10.2)$ in the post-PTX group (Table II and Figure $1)$. The inter-group differences were statistically significant $(p=0.020$; Figure 1). The ORR was $17 \%(\mathrm{n}=2)$ in the pre-PTX group and $70 \%(n=7)$ in the post-PTX group. The inter-group difference was significant ( $p=0.027$; Table II).

\section{Discussion}

In this study, we investigated the efficacy of paclitaxel-based chemotherapy administered before and after nivolumab in patients with HNC. Notably, we found improvements in ORR and TTP for paclitaxel-based chemotherapy after nivolumab compared with those before nivolumab in HNC patients.

Our study showed a significantly increased ORR for paclitaxel-based chemotherapy administered after nivolumab therapy (post-PTX, 70\%) than that before it (pre-PTX, 17\%). A retrospective study of 73 patients with NSCLC comparing ORRs for chemotherapy administered before and after antiPD-1/PD-L1 therapy showed that the ORR was significantly higher for the latter $(53.4 \%)$ than for the former $(34.9 \%$; $p=0.03$ ) (14). These results suggested that response to tumor for chemotherapy might be increased after anti-PD-1/PD-L1 therapy in multiple cancer types.

Moreover, we detected a better TTP for paclitaxel-based chemotherapy after nivolumab (post-PTX) compared with that before nivolumab (pre-PTX). On the other hand, a retrospective study of 102 patients with gastric cancer (GC) showed that ORR was higher in the patients who underwent chemotherapy after anti-PD1/PD-L1 therapy compared to

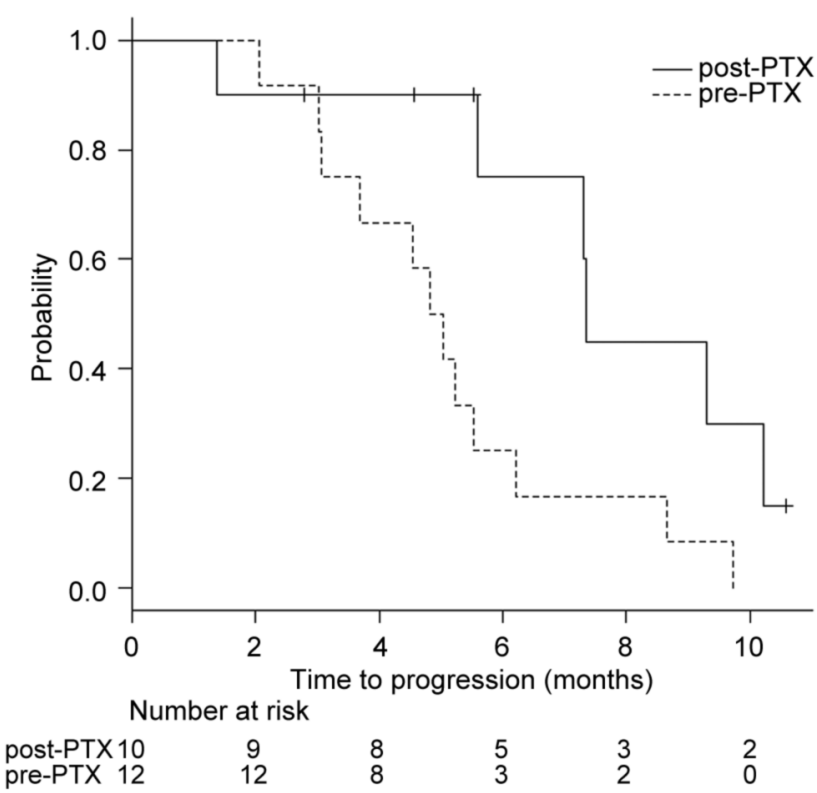

Figure 1. Kaplan-Meier curves for time to progression of paclitaxel containing therapy in 22 head and neck cancer patients.

those who received chemotherapy without prior anti-PD1/PD-L1 therapy, but there was no statistically significant difference in TTP (15). The gap between the efficacies of chemotherapy after nivolumab for HNC and that after antiPD-1/PD-L1 therapy for GC could be explained by the differences in the treatment lines between the HNC and the GC. The standard therapeutic lines of nivolumab or chemotherapy described above were administered later in GC (third- or later-line) than in HNC (second or more line). In our study, 21 of 22 (95\%) HNC patients received nivolumab or PTX-based chemotherapy before second-line treatment; however, GC patients in the previous study received chemotherapy for evaluation as forth or later-line treatment. Another hypothesis is that biological differences between GC and other cancers including HNC may also have affected this result. Therefore, additional basic research is needed.

The increased effect of paclitaxel-based chemotherapy after nivolumab could be biologically plausible. Previous studies have shown that paclitaxel modulates tumor immunity by several mechanisms: augmenting dendritic cell activation, promoting recognition of tumor cells and antitumor $\mathrm{CD}^{+}{ }^{+} \mathrm{T}$-cell phenotype, and abrogating regulatory $\mathrm{T}$ cells (16). The interplay of immunotherapy and chemotherapy could have harnessed synergic effect.

Several limitations of this study should be acknowledged. Firstly, this was a retrospective study with a small number of patients, and selection bias may have resulted from physicians' subjectivity in determining the sequence of chemotherapy and nivolumab. Secondly, the observation 
time was short, mainly because nivolumab was only approved for recurrent or metastatic HNC in Japan less than 3 years ago for HNC. We plan to continue accumulating data for a study with a larger number of patients.

In conclusion, this retrospective study evaluated the efficacies of chemotherapy administered before and after nivolumab in patients with HNC. Notably, we found that paclitaxel-based chemotherapy had a better ORR and a better trend of TTP for paclitaxel-based chemotherapy after nivolumab than before nivolumab in HNC patients. The sequential administration of anti-PD-1 therapy followed by paclitaxel-based chemotherapy could be a good strategy to maximize the efficacy of chemotherapy in HNC.

\section{Conflicts of Interest}

YS reports personal fees from ONO Pharmaceutical Co., Ltd, Bristol-Myers Squibb Company, MSD KK and TAIHO Pharmaceutical Co., Ltd, outside the submitted work. NF and JT report personal fees from Eisai. ST reports grants and personal fees from Bristol- Myers Squibb KK, grants and personal fees from ONO Pharmaceutical Co., Ltd, grants and personal fees from MSD, grants and personal fees from AstraZeneca, grants and personal fees from Chugai, and grants and personal fees from BAYER, outside the submitted work. The other Authors report no competing interests to disclose.

\section{Authors' Contributions}

YS designed the study and wrote the article. NF, YF, XW, TU, AO, $\mathrm{KN}, \mathrm{MO}, \mathrm{JT}, \mathrm{HM}$ and ST contributed critical revisions of the article. All Authors read and approved the final version of the article.

\section{Acknowledgements}

The Authors thank the medical staff of the Department of Head and Neck Surgery at the Cancer Institute Hospital, and the Japanese Foundation for Cancer Research for their support during this study.

\section{References}

1 Topalian SL, Drake CG and Pardoll DM: Immune checkpoint blockade: a common denominator approach to cancer therapy. Cancer Cell 27: 450-461, 2015. PMID: 25858804. DOI: 10.1016/j.ccell.2015.03.001

2 Postow MA, Callahan MK and Wolchok JD: Immune checkpoint blockade in cancer therapy. J Clin Oncol 33: 1974-1982, 2015. PMID: 25605845. DOI: 10.1200/JCO.2014.59.4358

3 Ferris RL, Licitra L, Fayette J, Even C, Blumenschein G, Harrington KJ, Guigay J, Vokes EE, Saba NF, Haddad R, Ramkumar S, Russell J, Brossart P, Tahara M, Colevas AD, Concha-Benavente F, Lynch M, Li L and Gillison ML: Nivolumab in patients with recurrent or metastatic squamous cell carcinoma of the head and neck: Efficacy and safety in checkmate 141 by prior cetuximab use. Clin Cancer Res 25: 5221-5230, 2019. PMID: 31239321. DOI: 10.1158/10780432.CCR-18-3944
4 Ferris RL, Blumenschein G, Fayette J, Guigay J, Colevas AD, Licitra L, Harrington KJ, Kasper S, Vokes EE, Even C, Worden F, Saba NF, Docampo LCI, Haddad R, Rordorf T, Kiyota N, Tahara M, Lynch M, Jayaprakash V, Li L and Gillison ML: Nivolumab vs. investigator's choice in recurrent or metastatic squamous cell carcinoma of the head and neck: 2-year long-term survival update of CheckMate 141 with analyses by tumor PDL1 expression. Oral Oncol 81: 45-51, 2018. PMID: 29884413. DOI: 10.1016/j.oraloncology.2018.04.008

5 Ma BBY, Lim W-TT, Goh B-CC, Hui EP, Lo K-WW, Pettinger A, Foster NR, Riess JW, Agulnik M, Chang AYC, Chopra A, Kish JA, Chung CH, Adkins DR, Cullen KJ, Gitlitz BJ, Lim DW, To K-FF, Chan KCACA, Lo YMDMD, King AD, Erlichman C, Yin J, Costello BA and Chan ATC: Antitumor activity of nivolumab in recurrent and metastatic nasopharyngeal carcinoma: An international, multicenter study of the mayo clinic phase 2 consortium (NCI-9742). J Clin Oncol 36: 14121418, 2018. PMID: 29584545. DOI: 10.1200/JCO.2017.77.0388

6 Sato Y, Fukuda N, Wang X, Urasaki T, Ohmoto A, Nakano K, Yunokawa M, Ono M, Sato Y, Mitani H, Tomomatsu J and Takahashi S: Efficacy of nivolumab for head and neck cancer patients with primary sites and histological subtypes excluded from the CheckMate-141 Trial. Cancer Manag Res Volume 12: 41614168, 2020. PMID: 32581587. DOI: 10.2147/CMAR.S249393

7 Borghaei H, Paz-Ares L, Horn L, Spigel DR, Steins M, Ready NE, Chow LQ, Vokes EE, Felip E, Holgado E, Barlesi F, Kohlhufl M, Arrieta O, Burgio MA, Fayette J, Lena H, Poddubskaya E, Gerber DE, Gettinger SN, Rudin CM, Rizvi N, Crina L, Blumenschein GR, Antonia SJ, Dorange C, Harbison $\mathrm{CT}$, Graf Finckenstein $\mathrm{F}$ and Brahmer JR: Nivolumab versus docetaxel in advanced nonsquamous non-small-cell lung cancer. N Engl J Med 373: 1627-1639, 2015. PMID: 26412456. DOI: 10.1056/NEJMoa1507643

8 Rittmeyer A, Barlesi F, Waterkamp D, Park K, Ciardiello F, von Pawel J, Gadgeel SM, Hida T, Kowalski DM, Dols MC, Cortinovis DL, Leach J, Polikoff J, Barrios C, Kabbinavar F, Frontera OA, De Marinis F, Turna H, Lee JS, Ballinger M, Kowanetz M, He P, Chen DS, Sandler A and Gandara DR: Atezolizumab versus docetaxel in patients with previously treated non-small-cell lung cancer (OAK): a phase 3, open-label, multicentre randomised controlled trial. Lancet 389: 255-265, 2017. PMID: 27979383. DOI: 10.1016/S0140-6736(16)32517-X

9 Motzer RJ, Escudier B, McDermott DF, George S, Hammers HJ, Srinivas S, Tykodi SS, Sosman JA, Procopio G, Plimack ER, Castellano D, Choueiri TK, Gurney H, Donskov F, Bono P, Wagstaff J, Gauler TC, Ueda T, Tomita Y, Schutz FA, Kollmannsberger C, Larkin J, Ravaud A, Simon JS, Xu L-A, Waxman IM and Sharma P: Nivolumab versus everolimus in advanced renal-cell carcinoma. N Engl J Med 373: 1803-1813, 2015. PMID: 26406148. DOI: 10.1056/NEJMoa1510665

10 Schvartsman G, Peng SA, Bis G, Lee JJ, Benveniste MFK, Zhang J, Roarty EB, Lacerda L, Swisher S, Heymach JV, Fossella FV, William WN, Roarty EB, Lee JJ, Benveniste MFK, Bis G, William WN, Fossella F V, Peng SA, Lacerda L, Swisher S, Schvartsman G and Zhang J: Response rates to single-agent chemotherapy after exposure to immune checkpoint inhibitors in advanced non-small cell lung cancer. Lung Cancer 112: 90-95, 2017. PMID: 29191606. DOI: 10.1016/j.lungcan.2017.07.034

11 Szabados B, van Dijk N, Tang YZ, van der Heijden MS, Wimalasingham A, Gomez de Liano A, Chowdhury S, Hughes 
S, Rudman S, Linch $M$ and Powles T: Response rate to chemotherapy after immune checkpoint inhibition in metastatic urothelial cancer. Eur Urol 73: 149-152, 2018. PMID: 28917596. DOI: $10.1016 /$ j.eururo.2017.08.022

12 Saleh K, Daste A, Martin N, Pons-Tostivint E, Auperin A, Herrera-Gomez RG, Baste-Rotllan N, Bidault F, Guigay J, Le Tourneau C, Saada-Bouzid E and Even C: Response to salvage chemotherapy after progression on immune checkpoint inhibitors in patients with recurrent and/or metastatic squamous cell carcinoma of the head and neck. Eur J Cancer 121: 123-129, 2019. PMID: 31574417. DOI: 10.1016/j.ejca.2019.08.026

13 Kanda Y: Investigation of the freely available easy-to-use software "EZR" for medical statistics. Bone Marrow Transplant 48: 452-458, 2013. PMID: 23208313. DOI: 10.1038/bmt. 2012.244

14 Park SE, Lee SH, Ahn JS, Ahn MJ, Park K and Sun JM: Increased response rates to salvage chemotherapy administered after PD-1/PD-L1 inhibitors in patients with non-small cell lung cancer. J Thorac Oncol 13: 106-111, 2018. PMID: 29101058. DOI: $10.1016 /$ j.jtho.2017.10.011
15 Kato K, Narita Y, Mitani S, Honda K, Masuishi T, Taniguchi H, Kadowaki S, Ura T, Ando M, Tajika M and Muro K: Efficacy of cytotoxic agents after progression on anti-PD-(L)1 antibody for pre-treated metastatic gastric cancer. Anticancer Res 40: $2247-$ 2255, 2020. PMID: 32234921. DOI: 10.21873/anticanres. 14187

16 Emens LA and Middleton G: The interplay of immunotherapy and chemotherapy: Harnessing potential synergies. Cancer Immunol Res 3: 436-443, 2015. PMID: 25941355. DOI: 10.1158/2326-6066.CIR-15-0064

Received December 30, 2020

Revised January 12, 2021

Accepted January 13, 2021 